\title{
A desigual divisão sexual do trabalho: um olhar sobre a última década
}

\author{
LUANA PASSOS DE SOUSA ${ }^{I}$ \\ e Dreggo Rocha GUEDES II
}

\section{Introdução}

1

HISTÓRIA do século XIX revela que havia, na sociedade de modo geral, uma nítida divisão entre domínio público e privado. Os homens “pertenciam” à esfera pública, pois desempenhavam de forma predominante o papel de provedor da família, e as mulheres "pertenciam" à esfera privada, uma vez que o cuidado do lar funcionava como atividade de contrapartida dado o sustento financeiro do marido.

Nessa dicotomia entre o público e o privado se consubstanciou a divisão sexual do trabalho, homens provedores e mulheres cuidadoras. Assim, durante um período considerável de tempo, as atribuições sociais, ao mesmo tempo que limitavam as mulheres a permanecerem no espaço privado, delegavam aos homens, como "destino natural", o espaço público. Com as transformações no cenário socioeconômico, com as revoluções culturais e a força do movimento feminista no século XX, novas configurações sociais foram surgindo, fragilizando de modo conjunto a dicotomia entre público e privado e o modelo homem provedor e mulher cuidadora.

O relaxamento das fronteiras entre o mundo produtivo (homens) e reprodutivo (mulheres) tem contribuído com a possibilidade de as mulheres participarem do mundo produtivo, mas não reveste o afastamento dos homens do mundo doméstico. Acontece que, através desse fenômeno, o adensamento das mulheres nas fronteiras públicas não é acompanhado de uma revisão dos limites das responsabilidades privadas femininas. Isso significa que a esfera de reprodução da família como educação e demais cuidados continua, em grande medida, a cargo das mulheres.

Desse modo, a dicotomia público/privado que está associada ao trabalho remunerado/não remunerado e que contribui com a divisão sexual do trabalho é reconfigurada, mas sem mudança significativa, ou estrutural, em sua essência. As atribuições socialmente definidas para homens e mulheres, no fim das contas, permanecem nas concepções culturais, uma vez que delegam ainda às mulheres as reponsabilidades da reprodução social. 
É sabido que o Brasil é marcado por uma acentuada desigualdade de gênero; no entanto, pouco foi investigado como se apresentam as assimetrias entre homens e mulheres nas regiões brasileiras.

Com base nessas considerações, o objetivo deste artigo é analisar e comparar os aspectos associados à divisão sexual do trabalho no Brasil e em suas regiões. É possível apontar elementos em comum e que, portanto, possuem características estruturais da sociedade brasileira, e os elementos que são específicos de cada região. A relevância desse trabalho é, com base nas características destacadas na análise, reforçar a necessidade de políticas públicas que aprimorem o Estado de Bem-Estar da sociedade brasileira.

O trabalho está dividido em quatro seções além desta introdução e das considerações finais. Na segunda seção são discutidas as relações estabelecidas entre os sexos e a divisão sexual do trabalho, fruto das relações sociais mediadas por relações de poder. Na terceira seção é analisado o trade-off entre trabalho e família que marca a vida das mulheres e como se apresenta para o Brasil a alocação do tempo de mulheres e homens em relação ao trabalho remunerado e não remunerado. E na quarta e última seção são analisados os aspectos da divisão sexual do trabalho para as regiões brasileiras.

\section{Divisão do trabalho e relações de sexo}

A não consideração dos afazeres domésticos como trabalho silenciou e tornou invisível, por muito tempo, relações assimétricas e de poder entre os sexos. Como as atividades domésticas eram baseadas nos vínculos de casamento e reciprocidades parentais, as relações de subalternidade e opressão entre os sexos ficavam escondidas na cumplicidade familiar, que reserva às mulheres $o$ amor e cuidado à família, e ao homem a provisão financeira. $\mathrm{O}$ curso da história delineou um modelo de família cuja protagonista, a mãe, seria a responsável por dispensar especial atenção ao cuidado e à educação dos filhos, assumindo a formação moral das crianças no interior dos lares. Nessa configuração, os espaços públicos seriam de direito dos homens, vistos como provedores e chefes da família (Scott apud Ramos, 2013).

A partir do momento em que o trabalho doméstico passou a ser analisado como atividade de trabalho, tanto quanto o trabalho profissional, caminhos foram abertos para pensar em termos de "divisão sexual do trabalho" (Hirata; Kergoat, 2007). A divisão sexual do trabalho toma como referência o trabalho, já as relações sociais de sexo transversalizam todos os campos do social (Hirata, 2010).

A divisão sexual do trabalho foi objeto de pesquisa em diversos países, mas foi na França, no início dos anos 1970, que as bases teóricas desse conceito se consolidaram, sob o impulso do movimento feminista. O paradigma da divisão sexual do trabalho fortaleceu o debate sobre o trabalho da mulher nos espaços público e privado (Castro, 1992), tirando da invisibilidade a reprodução social executada gratuitamente pelas mulheres. 
Para Hirata e Kergoat (2007), a relação social recorrente entre o grupo dos homens e o das mulheres é considerada "relações sociais de sexo". Para as autoras, a divisão sexual do trabalho é fruto da divisão social estabelecida nas relações sociais entre os sexos, divisão essa modulada histórica e socialmente e instrumento da sobrevivência da relação social entre os sexos.

A divisão do trabalho proveniente das "relações sociais de sexo" reservou às mulheres a esfera reprodutiva e aos homens, a esfera produtiva, estabelecendo uma relação assimétrica entre os sexos que cria e reproduz concomitantemente as desigualdades de papéis e funções na sociedade. As relações sociais entre os sexos se apresentam desiguais, hierarquizadas, marcadas pela exploração e opressão de um sexo em contraponto à supremacia do outro.

A divisão do trabalho que se estabeleceu entre os sexos atribuiu o cuidado do lar para a mulher, função, quando não invisível, tida como de pouco valor social. Enquanto a produção material foi atribuída aos homens, tarefa considerada de prestígio e que confere poder dentro da sociedade.

Histórica e culturalmente, especialmente dentro da sociedade capitalista, sempre coube à mulher a responsabilidade pelos cuidados com a casa e com a família, independentemente de sua idade, condição de ocupação e nível de renda. O trabalho doméstico recaía sobre as mulheres com base no discurso, vivo até hoje, da naturalidade feminina para o cuidado. Essa atribuição social do cuidado ao feminino, primeiramente, limitou a vida das mulheres ao espaço privado, e posteriormente, com as transformações socioeconômicas e a busca de independência feminina, marcou desvantagens em relação aos homens na atuação econômica e social.

O ingresso das mulheres no mundo econômico não equilibra as funções atribuídas aos sexos, ao contrário, reforça as desvantagens vividas pelas mulheres que atualmente compartilham com os homens, de forma equânime ou não, a provisão financeira da família juntamente com a responsabilidade da esfera reprodutiva. A saída do lar e as conquistas cada vez mais visíveis no âmbito público representaram uma revolução incompleta, uma vez que as mulheres ainda assumem praticamente sozinhas as atividades do espaço privado, o que perpetua uma desigual e desfavorável divisão sexual do trabalho para elas.

Para Bruschini (2006), o tempo econômico masculino é sempre maior do que o feminino e, por sua vez, o tempo feminino na reprodução social é maior do que o masculino. Segundo a autora, não há uma contrapartida de redução do tempo dedicado por elas à reprodução social, acontece apenas uma adição do tempo econômico ao da reprodução social.

Diferentes categorias de análise são utilizadas para compreender a assimetria da divisão do trabalho entre os sexos: i) a divisão sexual do trabalho e as relações sociais do sexo; ii) o gênero e as relações de gênero; iii) as diferenças de sexo; iv) a discriminação e as desigualdades (Hirata, 2010). Portanto, a compreensão da forma que se procede a divisão social e sexual do trabalho perpassa o entendimento das relações sociais, de poder e econômicas moduladas pela cultura ao longo da história. 
A relação entre produção e reprodução se materializa na relação entre trabalho remunerado e não remunerado, e nas relações sociais entre os sexos. Como "destino natural dos sexos" se define a produção e a remuneração aos homens, e a reprodução e o trabalho não remunerado às mulheres. É a dicotomia entre o público e o privado se consubstanciando no binário trabalho remunerado e não remunerado. Para Sorj (2004), o trabalho remunerado e o não remunerado são duas dimensões do trabalho social que estão intimamente relacionadas, prevalecendo a noção de que o trabalho para o mercado e a atividade doméstica são guiados por diferentes princípios, pois as regras do mercado se aplicam à produção, e o trabalho doméstico seria a contrapartida das mulheres no casamento pelo seu sustento.

A divisão sexual do trabalho é o que elucida o estreito vínculo entre trabalho remunerado e não remunerado. Articulando a esfera da produção econômica e da reprodução social, foi possível observar que as obrigações domésticas limitavam o desenvolvimento profissional das mulheres, implicando carreiras descontínuas, salários mais baixos e empregos de menor qualidade (Bruschini, 2006).

Marcam as atividades de trabalho estereótipos que associam o sexo e o par masculinidade/virilidade e feminilidade. A virilidade é associada ao trabalho pesado, penoso, sujo, insalubre, algumas vezes perigoso, já a feminilidade é associada ao trabalho leve, fácil, limpo, que exige paciência e minúcia (Hirata, 1995). A masculinidade foi associada ao homo economicus, aquele que age com racionalidade, e a feminilidade, associada ao sentimentalismo, muitas vezes irracional. Nessa lógica, ficaram reservadas aos homens as tarefas que geram mais retornos econômicos, e às mulheres, as tarefas que embora possam não gerar bons retornos econômicos têm ligação com o lado amoroso, cuidadoso, altruísta "feminino".

Essa oposição entre o masculino e o feminino, no entanto, vem sendo colocada em xeque à medida que as mulheres ocupam mais funções ditas masculinas no mercado de trabalho e na vida pública e os guetos femininos passam também a ser ocupados por homens. Vale ressaltar que o adensamento de mulheres nos espaços historicamente masculinos não significa alteração na essência da divisão social do trabalho, pois ainda há hierarquização do trabalho masculino como de maior valor do que o trabalho feminino.

As mudanças e as permanências da divisão do trabalho entre homens e mulheres ao longo da história revelam tanto o poder de persistência quanto de variabilidade das formas de trabalho dos homens e das mulheres. As relações sociais de sexo são dinâmicas e não lineares. Avanços e retrocessos acontecem continuamente, configurando novas relações em antigas tensões. Dados esses aspectos da discussão, a próxima seção visa discutir e apresentar como está configurada no Brasil, entre o período de 2004 e 2014, a divisão sexual do trabalho. O objetivo é compreender como essas relações estão postas e observar se existe algum indicativo que aponte para uma maior equalização dentro da relação entre os sexos. 


\section{Conflito entre trabalho e família: as "escolhas" das mulheres brasileiras entre trabalho remunerado e não remunerado}

O tempo, como outros recursos, tem uma dotação limitada. A alocação de horas em determinada atividade, do tipo trabalho remunerado, significa abrir mão do uso do tempo em outras tarefas, como cuidado doméstico. Acredita-se que esse conflito deveria ser comum e atingir a todos de forma semelhante, ou seja, o sexo da pessoa não deveria implicar pesos diferentes na opção de "mais trabalho" ou "mais família".

Nas relações sociais de sexo são atribuídas, de forma prioritária às mulheres, as tarefas referentes ao trabalho doméstico, e aos homens o trabalho produtivo. Isso faz que a alocação de tempo entre trabalho e família seja algo mais conflitante e marcante na vida das mulheres. Em geral, isso não acontece com os homens que têm como trade-off mais comum a opção entre trabalho e lazer. Essa naturalização dos distintos lugares sociais que devem ser assumidos por homens e mulheres faz que a "opção" das mulheres seja de forma comum por mais família e menos trabalho remunerado.

Em razão dessas atribuições sociais que delegam às mulheres o cuidado do lar, o espaço doméstico se tornou algo comum na vida delas. Ademais, entende-se que essas atribuições foram construídas ao longo do tempo na sociedade. Como lembram Araújo, Amorim e Ferreira (2004, p.3), "Nas sociedades igualitárias, ditas 'primitivas', nas quais não havia a divisão de classes, as relações de gênero eram a base da organização da sociedade e da divisão social do trabalho". Já nas sociedades capitalistas “[...] as relações de classe e de gênero são estruturantes e se superpõem".

À medida que tais atribuições passaram a ser questionadas pela mulher seja através de maior inserção produtiva para auxiliar no sustento da casa, como apontam Bruschini (1988; 1994) e Matos e Borelli (2012), seja pela própria necessidade dinâmica do sistema (Agénor; Canuto, 2015), ${ }^{1}$ ou por meio de movimentos políticos como o feminista - os papéis instituídos passaram a sofrer alterações (Passos, 2015). O trade-off entre trabalho e família se torna visível socialmente a partir desse momento em que as mulheres deixam sua função exclusiva de cuidadora do lar e passam a ser também trabalhadoras remuneradas.

A Tabela 1 mostra como a divisão dos cuidados domésticos é desigual entre os sexos e desfavorável às mulheres. A proporção de homens, na condição de pessoa de referência ou cônjuge, que realizaram afazeres domésticos não atingiu $60 \%$ ao longo da última década, contra mais de $90 \%$ para as mulheres. A despeito da baixa proporção, destacamos o aumento, de 2004 para 2014, de quase 7 pontos percentuais (p.p.) na participação dos homens nos afazeres domésticos na posição de chefe de família. Já na posição de cônjuge o aumento é inexpressivo. No caso das mulheres, o fato de ser cônjuge reforçou a participação nos cuidados domésticos, um patamar maior que o da pessoa de referência em torno de 5 p.p. em 2004, e 3 p.p. em 2014, aproximadamente. 
Tabela 1 - Proporção de pessoas com 16 anos ou mais que cuidavam dos afazeres domésticos por sexo e condição na família

\begin{tabular}{lll|ll}
\hline & Ano 2004 & & \multicolumn{2}{|c}{ Ano 2014 } \\
& Mulher & Homem & Mulher & Homem \\
Pessoa de Referência & $92,25 \%$ & $51,44 \%$ & $92,84 \%$ & $58,36 \%$ \\
Cônjuge & $97,16 \%$ & $46,55 \%$ & $95,70 \%$ & $46,64 \%$ \\
\hline
\end{tabular}

A participação das mulheres no mercado de trabalho tem forte ligação com os mecanismos à disposição destas para facilitar a conciliação entre o trabalho e família, uma vez que, como mostrado nos dados da Tabela 1 , o engajamento dos homens nas tarefas domésticas ainda é baixo. Quanto maior a desfamiliarização dos cuidados da figura feminina, maior tende a ser a inserção das mulheres no mercado de trabalho, em empregos formais e de jornadas integrais. A ausência ou pouca presença de mecanismos conciliadores das tarefas domésticas e o trabalho remunerado leva a uma sobrecarga laboral que pode ser considerada injusta para as mulheres, uma vez que por conta própria elas precisam mediar o trabalho pago com o não pago.

O Estado de Bem-Estar Social brasileiro se organizou com base num arranjo familiar que utiliza o trabalho feminino doméstico para suprir as lacunas dos serviços públicos e das políticas sociais (Fontoura et al., 2010). Tal elemento apresenta, atualmente, um cenário que, apesar da feminização do emprego, a inserção da mulher é mais precária, os trabalhos, mais informais, os tempos parciais e as remunerações, menores. Esses fatores tornam maior a limitação das mulheres para assumirem cargos de gerência e chefia.

A Pnad 2014 corrobora as informações supracitadas, destacam-se os seguintes fatos: as mulheres foram 19 p.p. menos economicamente ativas que os homens; estiveram 7 p.p. mais presentes no mercado informal; ganharam R $\$$ 493,00 a menos, em média; e estiveram 7 p.p. menos presentes em função de dirigente geral.

Ressalta-se que os constrangimentos vividos pelas mulheres no mundo do trabalho podem estar ligados diretamente às assimetrias criadas nas relações de sexo. O acentuado conflito entre trabalho e família é o resultado da não harmonização dos avanços femininos no campo profissional com o relaxamento das responsabilidades relativas ao cuidado familiar. Guedes e Araújo (2011) constatam que os avanços das mulheres no campo profissional não ocorrem concomitantemente ao processo de "desnaturalização" dos tradicionais papéis femininos e da desconcentração do trabalho reprodutivo na figura da mãe. Isso acarreta como consequência a postergação, em especial por parte das mulheres mais escolarizadas, da maternidade até um limite máximo possível, ou mesmo a exclusão da maternidade nos planos de algumas mulheres. Com base na Pnad 2014 constata-se que $81,80 \%$ das mulheres com menos de três anos de estudo 
tiveram filhos contra $61,39 \%$ das mulheres com mais de doze anos de estudo, o que indicia uma postergação ou a rejeição da maternidade por parte das mulheres mais escolarizadas.

Nas últimas décadas têm ocorrido, em nível global, amplas modificações na composição sexual do mercado de trabalho e nas relações entre trabalho e família. O modelo "tradicional" do homem provedor e da mulher cuidadora vem dando lugar a um modelo no qual as mulheres e os homens se inserem no mercado de trabalho, mas os cuidados com a família continuam sendo responsabilidade primária das mulheres (Sorj; Fontes; Machado, 2007). Essa responsabilização às mulheres dos serviços domésticos não remunerados implica menor disponibilidade de tempo e "disposição" feminina ao mercado de trabalho, configurando, como mostrado na Tabela 2, menor atividade econômica das mulheres em relação aos homens.

A proporção de mulheres pessoa de referência economicamente ativa, na última década, manteve-se em um patamar de $58 \%$ e $57 \%$ para cônjuge contra $83 \%$ dos homens referência na família e $84 \%$ cônjuge.

Tabela 2 - Proporção de pessoas com 16 anos ou mais que eram economicamente ativas por sexo e condição na família

\begin{tabular}{lcc|cl}
\hline & Ano 2004 & & Ano 2014 & \\
& Mulher & Homem & Mulher & Homem \\
Pessoa de Referência & $58,74 \%$ & $85,51 \%$ & $56,56 \%$ & $81,65 \%$ \\
Cônjuge & $57,11 \%$ & $84,10 \%$ & $57,79 \%$ & $84,79 \%$ \\
\hline
\end{tabular}

Fonte: Elaboração própria com base nos dados da Pnad 2004 e 2014.

As Tabelas 1 e 2 mostram como se configura a divisão sexual do trabalho brasileira, as mulheres assumem de forma preponderante as responsabilidades domésticas e os homens atuam marcadamente na atividade econômica. Além disso, é perceptível a vagarosa, quando não nula, mudança nas relações assimétricas dentro e fora do lar. "[...] A divisão sexual do trabalho parece estar submetida a uma lentidão que conduz mais ao deslocamento das fronteiras entre o masculino e o feminino que a supressão da própria divisão sexual do trabalho" (Hirata, 1995, p.45).

A divisão sexual do trabalho pode ser investigada com base na ideia de complementaridade entre os sexos, ou na ideia de uma conciliação dos papéis. Para Hirata (2015), a divisão sexual do trabalho pode tomar quatro formas: i) a forma de um modelo tradicional (mulheres cuidadoras e homens provedores); ii) a forma de um modelo de conciliação (as mulheres conciliam a vida profissional com a vida familiar); iii) modelo de parceria (mulheres e homens compartilham tarefas domésticas e cuidados da família); e iv) a forma de um modelo da delegação (mulheres delegam a outras mulheres suas atividades domésticas, o que ameniza a contradição e a tensão na vida do casal). 
As quatro formas parecem se manifestar no Brasil, porém, em intensidades distintas. Com a maior participação das mulheres no mundo laboral, o modelo tradicional vai cedendo espaço para o modelo de conciliação, cada vez um traço mais corriqueiro da sociedade brasileira. O modelo de delegação não tem proeminência no país, uma vez que o serviço doméstico pago está acessível apenas para a classe média e rica, e claramente a maior parte da população brasileira não se encontra nesses estratos sociais. $\mathrm{O}$ modelo que menos ecoa é o de parceria; desnecessário, por evidente, comprovar como poucas mulheres possuem em seus lares um compartilhamento equânime das tarefas de cuidado.

Alocação de horas no trabalho remunerado e não remunerado é reflexo da divisão do trabalho definida nas relações entre os sexos. Como pode ser visto nas Tabelas 3 e 4, as mulheres dedicam mais tempo ao cuidado doméstico não pago e os homens, mais tempo ao trabalho remunerado, confirmando o que já é sabido há algum tempo sobre a desigual e desfavorável divisão sexual do trabalho para as mulheres.

As mulheres vêm dedicando, independentemente da posição na família, mais que o dobro de horas aos cuidados domésticos que os homens na última década, e, no mínimo, seis horas a menos em trabalho remunerado. Para as mulheres na posição de cônjuge a situação é ainda pior, com no mínimo nove horas a menos de trabalho pago, e quatro horas a mais de afazeres domésticos, o que evidencia que relações maritais robustecem os papéis sociais estereotipados.

$\mathrm{Na}$ última década o Brasil logrou muitos avanços sociais, o que fica atestado na queda da pobreza e desigualdade de renda. No entanto, os dados das Tabelas 3 e 4 permitem inferir que as relações de gênero permanecem estáveis, sem nenhuma reversão na desigual e desfavorável divisão sexual do trabalho para as mulheres.

Tabela 3 - Tempo médio de afazer doméstico* de pessoas com 16 anos ou mais por sexo e condição na família

\begin{tabular}{lcc|cl}
\hline & Ano 2004 & & Ano 2014 & \\
& Mulher & Homem & Mulher & Homem \\
Pessoa de Referência & 25 & 11 & 25 & 11 \\
Cônjuge & 31 & 11 & 29 & 10 \\
\hline
\end{tabular}

Fonte: Elaboração própria com base nos dados da Pnad 2004 e 2014.

*A variável "afazeres domésticos" distingue-se do "emprego doméstico". A primeira referese ao trabalho não remunerado realizado no lar, enquanto a segunda corresponde ao trabalho remunerado na prestação de serviços domésticos. 
Tabela 4 - Tempo médio de horas trabalhadas de pessoas com 16 anos ou mais por sexo e condição na família

\begin{tabular}{lcc|cl}
\hline & Ano 2004 & & Ano 2014 & \\
& Mulher & Homem & Mulher & Homem \\
Pessoa de Referência & 37 & 45 & 36 & 42 \\
Cônjuge & 33 & 45 & 34 & 43 \\
\hline
\end{tabular}

Fonte: Elaboração própria com base nos dados da Pnad 2004 e 2014.

A inserção da mulher de forma parcial no mercado de trabalho tem fortes vínculos com a provisão insuficiente de mecanismos de conciliação entre trabalho e família, em especial para as mulheres mais pobres, que não podem se valer do modelo de delegação e não têm acesso às instituições privadas de provisão de cuidados. No que se refere ao cuidado de crianças pequenas, a situação mais delicada das mulheres pobres é perceptível no fato de apenas $14 \%$ das crianças de 0 a 3 anos, de famílias do primeiro decil de renda, terem recebido cuidados formais, por meio de creches, em 2014.

No Brasil não existem instituições públicas para atender todas as crianças desde a tenra idade, nem educação em tempo integral para todas as faixas etárias. Há ainda menos serviços públicos que atendam a demanda de cuidados e atenção exigida pela população idosa e deficiente, o que penaliza as mulheres que decidem pela inserção no mercado de trabalho com jornadas remuneradas menores, empregos mal remunerados, e com excessiva carga de trabalho quando somado o trabalho reprodutivo ao trabalho produtivo.

A jornada total de trabalho das mulheres, como mostra a Tabela 5 , foi por volta de oito horas a mais do que a dos homens, revelando a sobrecarga de trabalho que têm as mulheres em razão da desigual divisão das tarefas no âmbito privado. A realização de todas as tarefas delegadas socialmente às mulheres tarefas de preparar ou providenciar a comida, cuidar das crianças, dos idosos, dos enfermos e das pessoas com deficiência, manter a higiene do espaço doméstico e das roupas dos membros da família, zelar pelos cuidados de saúde e de educação de todos, além de outras atribuições presentes em alguns contextos específicos, como providenciar água para a família, plantar e colher o alimento - juntamente com o trabalho para o mercado, gera uma injusta sobrecarga laboral para as mulheres (Fontoura et al., 2010). 
Tabela 5 - Jornada semanal total de pessoas com 16 anos ou mais por sexo e condição na família

\begin{tabular}{lcc|cl}
\hline & Ano 2004 & & Ano 2014 & \\
& Mulher & Homem & Mulher & Homem \\
Pessoa de Referência & 62 & 56 & 61 & 53 \\
Cônjuge & 64 & 56 & 63 & 53 \\
\hline
\end{tabular}

Fonte: Elaboração própria com base nos dados da Pnad 2004 e 2014.

Apesar de o cuidado continuar a cargo das mulheres, o aumento da demanda por cuidados no momento que a oferta privada não remunerada deles está se reduzindo tem dado destaque para a crise de cuidados que as sociedades começam a enfrentar. O envelhecimento da população e a entrada massiva das mulheres no mercado de trabalho, assim como os novos arranjos familiares chamam a atenção para a importância das ações reprodutivas na sociedade, que por muito tempo foi realizada de forma silenciosa e gratuita pelas mulheres dentro de seus lares.

A crise de cuidados da modernidade tem fortalecido a reivindicação do movimento feminista pela provisão pública de serviços de cuidados e pela desnaturalização da função de cuidadora das mulheres. Cada dia as mulheres aceitam menos os deveres de prover cuidados para a família, que socialmente acabam sendo, em alguma medida, impostos a ela e passam a requerer seu direito de participação da vida pública em igualdade de condição com os homens.

A próxima seção apresenta esses elementos discutidos na esfera do Brasil para a esfera regional. É interessante também observar como algumas regiões diferem entre si no que se refere às relações entre os sexos.

\section{Comportamento regional da divisão sexual do trabalho}

Em que pesem os avanços galgados pelas regiões mais pobres do país na última década, a assimetria regional ainda é um traço marcante no Brasil. ${ }^{2}$ Essa heterogeneidade econômica que marca o território brasileiro faz surgir o questionamento a respeito de como se comportam as assimetrias de gênero e a divisão sexual do trabalho entre as regiões brasileiras.

As regiões refletem de forma similar as desigualdades, ou são dispares em suas contribuições para a média nacional? De modo geral, o Brasil apresenta uma acentuada desigualdade na divisão sexual do trabalho, e relega às mulheres uma participação social e profissional atenuada em relação à participação masculina. Tais fatos serão apresentados na sequência para todas as regiões brasileiras.

Como mostrado na Tabela 6 , em todas as regiões do Brasil o percentual de mulheres que realizaram afazeres domésticos é quase ou mais de $90 \%$, enquanto os homens não passam da casa dos 60\%. Comparando os anos é possível observar que, em média, o percentual de homens que realizaram afazeres domésticos cresceu quase 4 p.p., e o percentual feminino, por seu turno, reduziu 2 p.p. A 
diferença entre eles no período diminuiu por volta de 5 p.p. Importante frisar que em todas as regiões do Brasil os homens aumentaram a participação nos afazeres domésticos, enquanto as mulheres reduziram. Passado uma década, marcada pelos avanços sociais inclusivos (cf. Campello; Neri, 2013), esses números apenas ensejam primeiros passos para maior igualdade nas relações de gênero. O Sul desponta como a região com maior participação masculina nas atividades domésticas, enquanto o Nordeste, apesar de ter aumentando a participação masculina em quase 3 p.p., encontra-se na "lanterna" das regiões.

A participação econômica se apresenta, em todas as regiões, com uma menor atuação das mulheres ante os homens. É possível visualizar, na Tabela 7, que em todas as regiões do Brasil o percentual de homens que participam da atividade produtiva atingiu ou superou $80 \%$, enquanto as mulheres não ultrapassaram os $65 \%$. A comparação dos anos mostra que houve uma queda de participação tanto para as mulheres quanto para os homens, sendo mais acentuado para os últimos e para a Região Sul. No caso das mulheres parece haver uma estabilidade, nem avanços nem retrocessos, na atividade econômica na última década. A diferença de atividade econômica dos homens para as mulheres saiu de um patamar de 25\%, em 2004, para 22\%, em 2014. A lenta queda ainda deixa preocupações quanto à participação dos homens em comparação com a das mulheres no mercado de trabalho. A Região Norte se destaca nesse quesito pela maior distância de participação entre os gêneros.

Tabela 6 - Afazer doméstico (2004 x 2014) 2004

\begin{tabular}{l|r|r|c}
\hline Região & Masculino & Feminino & Diferença \\
\hline Sul & $60,31 \%$ & $93,48 \%$ & $33,17 \%$ \\
\hline Sudeste & $45,53 \%$ & $90,75 \%$ & $45,22 \%$ \\
\hline Nordeste & $40,49 \%$ & $91,77 \%$ & $51,28 \%$ \\
\hline Centro-Oeste & $48,19 \%$ & $91,38 \%$ & $43,19 \%$ \\
\hline Norte & $47,16 \%$ & $92,84 \%$ & $45,68 \%$ \\
\hline Média & $48,34 \%$ & $92,04 \%$ & $43,71 \%$ \\
\hline
\end{tabular}

2014

\begin{tabular}{l|c|c|c}
\hline Região & Masculino & Feminino & Diferença \\
\hline Sul & $61,39 \%$ & $91,51 \%$ & $30,12 \%$ \\
\hline Sudeste & $52,26 \%$ & $88,97 \%$ & $36,71 \%$ \\
\hline Nordeste & $43,47 \%$ & $89,69 \%$ & $46,22 \%$ \\
\hline Centro-Oeste & $52,15 \%$ & $90,76 \%$ & $38,61 \%$ \\
\hline Norte & $51,84 \%$ & $91,50 \%$ & $39,66 \%$ \\
\hline Média & $52,22 \%$ & $90,49 \%$ & $38,26 \%$ \\
\hline
\end{tabular}

Fonte: Elaboração própria com base nos dados da Pnad 2004 e 2014. 
Tabela 7 - Pessoas economicamente ativas (2004 x 2014)

\begin{tabular}{l|c|c|c}
2004 & Masculino & Feminino & Diferença \\
\hline Região & $85,36 \%$ & $63,10 \%$ & $-22,26 \%$ \\
\hline Sul & $80,52 \%$ & $56,89 \%$ & $-23,63 \%$ \\
\hline Nudeste & $82,12 \%$ & $55,60 \%$ & $-26,52 \%$ \\
\hline Centro-Oeste & $85,35 \%$ & $59,76 \%$ & $-25,59 \%$ \\
\hline Norte & $85,95 \%$ & $57,80 \%$ & $-28,15 \%$ \\
\hline Média & $83,86 \%$ & $58,63 \%$ & $-25,23 \%$ \\
\hline 2014 & Masculino & Feminino & Diferença \\
\hline Região & $80,12 \%$ & $60,81 \%$ & $-19,31 \%$ \\
\hline Sul & $78,30 \%$ & $57,50 \%$ & $-20,80 \%$ \\
\hline Sudeste & $78,22 \%$ & $53,33 \%$ & $-24,89 \%$ \\
\hline Nordeste & $82,00 \%$ & $59,54 \%$ & $-22,46 \%$ \\
\hline Centro-Oeste & $81,17 \%$ & $55,04 \%$ & $-26,13 \%$ \\
\hline Norte & $79,96 \%$ & $57,24 \%$ & $-22,72 \%$ \\
\hline Média
\end{tabular}

Fonte: Elaboração própria com base nos dados da Pnad 2004 e 2014.

Nos termos de participação nas atividades produtivas e reprodutivas, as regiões têm comportamentos similares, não sendo possível concluir pela maior igualdade nas relações de gênero em nenhuma delas. Parece que nesse quesito as regiões “em nada” são heterogêneas.

$\mathrm{Na}$ alocação de tempo para a família prevalece, em todas as regiões, o papel de cuidadora assumido pelas mulheres, e a não responsabilização dos homens pelas atividades domésticas. Como pode ser visto na Tabela 8 , as mulheres gastam, independentemente da região, doze horas a mais (no mínimo) que os homens em afazeres domésticos. A comparação dos anos mostra que para os homens ocorreu nas regiões Sudeste e Nordeste uma diminuição leve do tempo gasto com afazeres domésticos, para o Sul houve um aumento irrisório e para o Norte e Centro-Oeste, um aumento um pouco mais expressivo. Por outro lado, a quantidade de horas dedicadas ao lar pelas mulheres sofreu redução, sendo essa mais significativa que o aumento no número de horas dos homens. O fato corrobora a suposição de que uma crise de cuidados privados não remunerados paira sobre a sociedade brasileira, já que a redução da provisão de cuidados por parte da mulher não é acompanhada na mesma proporção pelo aumento da oferta dos homens. Nas regiões Sul e Nordeste a diminuição na quantidade de horas trabalhadas em casa pelas mulheres foi mais contundente, em média três horas a menos. Nas demais regiões, apesar de ter diminuído, tal redução foi inexpressiva. As diferenças regionais foram pouco acentuadas e todas as regiões apresentaram uma desigual divisão sexual do trabalho, não podendo 
ser conferido a nenhuma delas o título de modelo de compartilhamento entre homens e mulheres nas atividades de cuidado.

No tempo de trabalho remunerado a dedicação dos homens é mais acentuada do que a das mulheres para qualquer região do país. No caso das mulheres, o trade off entre trabalho e família tende, devido a relações sociais de reprodução, mais para a família, ocasionando uma menor disponibilidade de tempo para as atividades remuneradas.

Como atestado na Tabela 9, os homens, diferentemente das mulheres, assumem uma jornada integral. A diferença de tempo remunerado é de no mínimo cinco horas a menos para as mulheres, o que ocasiona uma inserção parcial, e muitas vezes precarizada no mercado de trabalho. Na última década houve uma redução do diferencial de horas trabalhadas por gênero, mas não em favor de mais tempo remunerado para as mulheres. O Nordeste se apresenta como a região onde as mulheres têm a menor jornada de trabalho pago, e o Sudeste, como a maior. Nesse aspecto também nenhuma região ocupa lugar de destaque em prol da equânime divisão sexual do trabalho.

O comparativo dos aspectos da divisão sexual do trabalho por região incita a conclusão de que as relações assimétricas de gênero nas regiões do Brasil são bastante homogêneas. Em alguns quesitos as regiões se destacam como menos ou mais desiguais, mas não é perceptível uma hierarquização robusta, e nenhuma hipótese explicativa aqui foi levantada. Possíveis respostas ficam para investigações futuras em uma análise que possa ser mais específica acerca da heterogeneidade das relações de gênero nas regiões.

Tabela 8 - Horas de afazeres domésticos (2004 x 2014)

\begin{tabular}{l|c|c|c}
\multicolumn{5}{l|}{2004} & Masculino & Feminino & Diferença \\
\hline Região & 10,39 & 26,10 & 15,71 \\
\hline Sul & 11,14 & 26,71 & 15,57 \\
\hline Sudeste & 11,22 & 29,25 & 18,03 \\
\hline Nordeste & 9,85 & 25,52 & 15,67 \\
\hline Centro-Oeste & 10,55 & 24,60 & 14,05 \\
\hline Norte & 10,63 & 26,44 & 15,81 \\
\hline Média &
\end{tabular}

2014

\begin{tabular}{l|c|c|c}
\hline Região & Masculino & Feminino & Diferença \\
\hline Sul & 10,51 & 23,51 & 13,00 \\
\hline Sudeste & 10,91 & 25,05 & 14,14 \\
\hline Nordeste & 11 & 27,01 & 16,01 \\
\hline Centro-Oeste & 10,57 & 24,48 & 13,91 \\
\hline Norte & 11,58 & 24,23 & 12,65 \\
\hline Média & 10,914 & 24,86 & 13,94 \\
\hline
\end{tabular}

Fonte: Elaboração própria com base nos dados da Pnad 2004 e 2014. 
Tabela 9 - Horas trabalhadas (2004 x 2014)

2004

\begin{tabular}{l|c|c|c}
\hline Região & Masculino & Feminino & Diferença \\
\hline Sul & 44,87 & 36,04 & $-8,83$ \\
\hline Sudeste & 44,91 & 37,32 & $-7,59$ \\
\hline Nordeste & 41,69 & 32,15 & $-9,54$ \\
\hline Centro-Oeste & 46,43 & 36,45 & $-9,98$ \\
\hline Norte & 43,30 & 33,86 & $-9,44$ \\
\hline Média & 44,24 & 35,16 & $-9,08$ \\
\hline
\end{tabular}

2014

\begin{tabular}{l|c|c|c}
\hline Região & Masculino & Feminino & Diferença \\
\hline Sul & 42,5 & 36,59 & $-5,91$ \\
\hline Sudeste & 42,67 & 37,05 & $-5,62$ \\
\hline Nordeste & 39,34 & 32,08 & $-7,26$ \\
\hline Centro-Oeste & 43,13 & 36,82 & $-6,31$ \\
\hline Norte & 40,26 & 33,45 & $-6,81$ \\
\hline Média & 41,58 & 35,20 & $-6,38$ \\
\hline
\end{tabular}

Fonte: Elaboração própria com base nos dados da Pnad 2004 e 2014.

\section{Considerações finais}

Durante um período considerável de tempo, as mulheres estiveram restritas ao espaço doméstico, tendo seu direito de interagir nos espaços políticos e nas questões sociais cerceados. Esse aspecto se deveu, principalmente, ao lugar de cuidadora ocupado pela mulher na sociedade. Com base na discussão feita neste artigo, essa atribuição "feminina" contribuiu para uma separação fundamental entre os sexos na esfera pública e privada, e entre as "escolhas" de trabalho remunerado e trabalho não remunerado. Nessa dicotomia de espaços e funções socais foram destinados aos homens os espaços públicos e as atividades produtivas remuneradas e às mulheres, os espaços privados e as funções reprodutivas gratuitas.

Essas relações sociais assimétricas entre os sexos podem ser consideradas fator principal da divisão sexual do trabalho que configurou um modelo de homens provedores e mulheres cuidadoras. Ao longo da história esse modelo marcou as sociedades ocidentais, mas com os novos arranjos familiares, a feminização do emprego, a necessidade de contribuir com o sustento familiar e o envelhecimento da população, tal modelo foi se enfraquecendo.

Com a crise de cuidados privados que ganha corpo nas sociedades contemporâneas, este trabalho se propôs a investigar as novas e velhas configurações da divisão sexual do trabalho no Brasil e em suas regiões no recorte temporal da última década. Os resultados, que podem ser considerados preliminares, pois visam apresentar um panorama geral da situação da mulher 
no Brasil contemporâneo, apontam para a não equalização da divisão social do trabalho no país.

Em uma comparação aproximada com o trabalho de Bruschini (1988), que apontou, com base em dados do Instituto Brasileiro de Geografia e Estatística (IBGE), que a participação das mulheres no total da força de trabalho nas cidades saiu de 22,3\% no ano de 1970 para 30,6\% no ano de 1983 , percebe-se que o quadro atual é bastante inclusivo para as mulheres no mercado de trabalho $58 \%$ das mulheres, em média, compunham a população economicamente ativa em 2014 (dados Pnad). Por outro lado, dados os fatores que compõem essa elevação na participação das mulheres no mercado de trabalho nacional, entendese que tal avanço não foi capaz de equalizar a divisão sexual do trabalho no país. Permanece ainda uma separação laboral que reserva aos homens, de forma predominante, os espaços produtivos, apesar de ter havido uma elevação em sua participação doméstica, e às mulheres uma maior participação no mercado de trabalho, mas que não veio acompanhada de uma compensação na realização do trabalho doméstico. Essa atividade continua como tarefa exclusiva e pouco compartilhada com os homens.

O contraponto entre as regiões brasileiras nos aspectos da divisão sexual do trabalho evidencia que as relações assimétricas de gênero nas regiões do Brasil são pouco heterogêneas. Em que pese em alguns quesitos as regiões se destacarem mais em prol da igualdade ou da desigualdade, é pouco perceptível um escalar das relações de gênero entre as regiões.

Da discussão feita no texto, extraem-se alguns questionamentos que podem ser subsídios para pesquisas futuras e contribuir, em alguma medida, para explicar o atual quadro da divisão sexual do trabalho no Brasil e em suas regiões, são eles: A educação seria um fator que exerceria algum tipo de contribuição decisiva? Até que ponto o grau de escolarização feminina poderia contribuir com a maior equalização da divisão sexual do trabalho? Se a média de anos de escolaridade for maior para determinadas regiões do país, não seria possível esperar maior participação masculina nessas? No entanto, é possível que exista algum limite superior que interfira na participação masculina quando se trata das tarefas compartilhadas? Se sim, quais motivos o explicariam? Acredita-se que esses são apenas alguns fatores que poderiam contribuir para melhor explicar o quadro da atual divisão sexual do trabalho no país e em suas regiões. Pesquisas nessa direção são importantes para consolidar o Estado de Bem-Estar Social brasileiro, e necessárias para ampliar as políticas de igualdade entre os gêneros no Brasil.

\section{Notas}

l Os autores analisam o impacto de longo prazo das políticas destinadas a promover a igualdade de gênero sobre o crescimento da economia brasileira. 
2 Para um debate teórico sobre os aspectos da desigualdade regional no Brasil ver Pessôa (2001), e para uma análise empírica acerca do mesmo tema, ver Figueiredo e Pôrto Júnior (2015).

\section{Referências}

AGÉNOR, P. R.; CANUTO, O. Gender equality and economic growth in Brazil: A long-run analysis. Journal of Macroeconomics, v.43, p.155-72, mar. 2015.

ARAÚJO, A. M. C.; AMORIM, E. R. A.; FERREIRA, V. C. Os sentidos do trabalho da mulher no contexto da reestruturação produtiva. In: CONGRESSO LUSO-AFRO BRASILEIRO DE CIÊNCIAS SOCIAIS. VIII. Coimbra, Anais... Coimbra, Portugal, 2004.

BRUSCHINI, C. Mulher e trabalho: uma avaliação da década da mulher (1975-1985). In: CARVALHO, N. V. (Org.) A condição feminina. São Paulo: Vértice; Editora Revista dos Tribunais, 1988.

O trabalho da mulher brasileira nas décadas recentes. Estudos Feministas, Florianópolis, p.179-99, jan. 1994. Disponível em: <https://periodicos.ufsc.br/index. $\mathrm{php} / \mathrm{ref} /$ article/view/16102>.

Trabalho doméstico: inatividade econômica ou trabalho não-remunerado? $R$. Bras. Est. Pop., São Paulo, v.23, n.2, p.331-53, jul./dez. 2006.

CAMPELlO, T.; NERI, M. C. (Org). Programa Bolsa Familia: uma década de inclusão e cidadania. Brasília: Ipea, 2013.

CASTRO, M. G. O conceito de gênero e as análises sobre mulheres e trabalho: notas sobre impasses teóricos. Cad. CRH, Salvador, n.17, p.80-105, 1992.

FIGUEIREDO, E.; PÔRTO JÚNIOR, S. S. Persistência das desigualdades regionais no Brasil: polarização e divergência. Nova Economia, Belo Horizonte, v.25, n.1, p.195208, jan.-abr. 2015.

FONTOURA, N. et al. Pesquisas de uso do tempo no Brasil: contribuições para a formulação de políticas de conciliação entre trabalho, família e vida pessoal. Revista Econômica, Rio de Janeiro, v.12, n.1, p.11-46, jun. 2010.

GUEDES, M. C.; ARAÚJO, C. Desigualdades de gênero, família e trabalho: mudanças e permanências no cenário brasileiro. Revista Gênero, v.12, p.61-79, 2011.

HIRATA, H. Divisão, relações sociais de sexo e do trabalho: contribuição à discussão sobre o conceito de trabalho. Em Aberto, Brasília, ano 15, n.65, p.39-49, jan./mar. 1995.

Mundialização, divisão sexual do trabalho e movimentos feministas transnacionais. Revista Feminista, Recife, n.2, 2010.

. Mudanças e permanências nas desigualdades de gênero: divisão sexual do trabalho numa perspectiva comparada. Friedrich Ebert Stiftung Brasil, n.7, 2015.

HIRATA, H.; KERGOAT, D. Novas configurações da divisão sexual do trabalho. Cadernos de Pesquisa, v.37, n.132, p.595-609, set./dez. 2007.

MATOS, M. I.; BORELLI, A. Espaço feminino no mercado produtivo. In: PINSKY, C. B.; PEDRO, J. M. (Org.) Nova história das mulheres. São Paulo: Contexto, 2012. 
PASSOS, L. Bolsa Família: socializando cuidados e mudando as relações de gênero? Niterói, 2015. Dissertação (Mestrado) - Faculdade de Economia, Universidade Federal Fluminense. Niteroi, 2015.

PESSÔA, S. Existe um problema de desigualdade regional no Brasil? In: ENCONTRO NACIONAL DE ECONOMIA, XXIX. Salvador. Anais... Salvador, 2001.

RAMOS, G. S. Leitura feminista da história das mulheres no Brasil. Revista Estudos Feministas, v.21, n.3, p.1232-5, dez. 2013.

SORJ, B. Trabalho remunerado e trabalho não remunerado. In: OLIVEIRA, S.; RECAMÁN, M.; VENTURI, G. (Org.) A mulber brasileira nos espaços público e privado. São Paulo: Fundação Perseu Abramo, 2004.

SORJ, B.; FONTES, A.; MACHADO, D. C. Políticas e práticas de conciliação entre família e trabalho no Brasil. Cadernos de Pesquisa, v.37, n.132, p.573-94, 2007.

RESUMO - Este artigo objetiva analisar a divisão sexual do trabalho no Brasil e entre suas regiões. Para tanto, foram realizadas estatísticas descritivas, com base na Pnad 2004 e 2014, da participação no mercado de trabalho, da participação nos afazeres domésticos, das horas de afazeres domésticos e das horas trabalhadas. Os resultados revelam que a divisão sexual do trabalho é desigual e desfavorável para as mulheres brasileiras, não havendo muita heterogeneidade entre as regiões.

PALAVRAS-CHAVE: Trabalho produtivo, Trabalho reprodutivo, Políticas públicas, Gênero. ABSTRACT - This article aims to analyze and compare aspects of the gender-based division of labor between the regions of Brazil. To this end, we performed descriptive statistical analyses of participation in the labor market, participation in domestic activities, hours of housework and total hours worked. The results reveal that the gender-based division of labor is unequal and unfavorable to Brazilian women and that there is not great heterogeneity between regions.

KEYWORDS: Productive labor, Reproductive labor, Public policy, Gender.

Luana Passos de Souza é doutoranda do Programa de Pós-Graduação em Economia da Universidade Federal Fluminense (UFF). Pesquisadora do Programa Nacional de Pesquisa para o Desenvolvimento (PNPD) no Instituto de Pesquisa Econômica Aplicada. Consultora da Organização Internacional do Trabalho (OIT) no projeto de Combate ao Trabalho Forçado. @- luanapassos_s@hotmail.com

Dyeggo Rocha Guedes é doutorando do Programa de Pós-Graduação em Economia da Universidade Federal do Rio Grande do Sul. @-dyeggoguedes@gmail.com

Recebido 20.4.2016 e aceito 3.5.2016.

I Programa de Pós-Graduação em Economia da Universidade Federal Fluminense, Nite roi/Rio de Janeiro, Brasil.

II Programa de Pós-Graduação em Economia da Universidade Federal do Rio Grande do Sul, Porto Alegre/Rio Grande do Sul, Brasil. 
